\title{
Clinical conferences for physicians: Who sets the agenda?
}

\author{
T.R. Abakumova, A.F. Safina and L.E. Ziganshina* \\ Kazan (Volga region) Federal University, Department of Basic and Clinical Pharmacology,
} Kazan, Russia

*Corresponding author. E-mail: lezign@gmail.com

BACKGROUND: Clinical conferences are generally defined as scheduled events at which practicing physicians themselves present to their colleagues interesting clinical cases, share their new experiences and learn about the latest achievements of medical science and practice. The value of a clinical conference is thought to be in direct communication between physicians, in analysis of topical issues in a given specialty with the aim to improve the quality of care. Speakers based on their own observations and studies reveal the most urgent problems, analyze results and offer potential decisions to their colleagues interested in the same questions. The event format may be different: workshops, highly specialized sections, round tables and seminars with participation of the leading specialists in a given field. These conferences are generally organised by the Ministries and Departments of Health, by leading research and/or educational institutions in the field, by recognised medical centres and other institutions. Recently pharmaceutical companies got actively involved in medical events, acting as sponsors of various scientific conferences and congresses, however threatening the mission of these events [1]. This brings up some uneasy questions: who are the medical conferences for? Who is in charge of setting the conference agenda? Do they contribute to evidence-based medicine; do they contribute to better health? Unfortunately, there is a trend to duplication or multiplication of conferences: various agencies and departments deliver the same conferences, presentations at which are often pre-arranged by pharmaceutical companies and do not have clear scientific novelty, while the conferences themselves have largely transformed into advertising of new pharmaceuticals or new technologies [2]. Pharmaceutical corporations sponsor invited speakers paying for their trips and paying honoraria, organising cocktail parties as part of medical activities. With the help of leading experts with impressive titles serving as speakers at the conferences, pharmaceutical companies are trying to be as close as possible to routine practice of prescribing of certain drugs, manipulating evidence, controlling scientific societies as well as the process of clinical guideline development and publication of research results [3]. The degree of expert involvement depends on their level of influence [4].

OBJECTIVE: We aimed to study how often regular medical practitioners attend these conferences; to analyse who were keynote speakers and where they were coming from; to identify which organizations were responsible for organisation of these conferences and for sending out invitations to these conferences and for disseminating information about them.

METHODS: We summarized all the invitations (printed on paper) received by one regular medical practitioner employed with the outpatient clinical of the city of Kazan for the period of two years (20122013). 
RESULTS: During the study period (2012-2013), a regular medical practitioner received 47 printed paper invitations to scientific conferences: 22 in 2012 and 25 in 2013. The conferences were not distributed evenly over the months of the years. November appeared to be the month with the highest density/ number of medical conferences: 7 conferences in 2012 and 10 in 2013. If the distribution was even, then we could calculate the number per month dividing the number per year by 9 active months (excluding July, August and September). This resulted in 2.4 and 2.8 conferences per month. Among these studied conferences 4 were organized by public health agencies: invitation tickets were accompanied by the corresponding official order to organise a conference, issued by the Health Department. Noteworthy, that 2 of these conferences were held in conference rooms of the largest hotels of the city. Forty-one out of 47 medical conferences were sponsored by big pharma: either jointly with the major medical higher educational institutions of the city or plainly by pharmaceutical companies. Seventeen conferences were held during official working hours, in the first half of the day. Not only the logo of the pharmaceutical companies was printed on invitation tickets, but there was also an advert of the promoted pharmaceutical brand.

Nine conference invitations contained invitation to dinner. In one of the invitations to a conference on neuroscience it was written: "dinner under the unforgettable music". Two conference invitations contained invitation to a lunch. Programs of 20 conferences (which were included) listed guest lecturers, coming from the leading medical universities in Moscow and St. Petersburg. Opinion leaders' involvement: some of the leading experts acted as speakers from 4 to 7 conferences a month in this sample conference invitations package of a regular polyclinic physician.

CONCLUSIONS: In 2012-2013 health practitioners were invited to attend medical conferences regularly, at least 2 times a month, with November being the busiest month. The keynote speakers were the opinion leaders from the local medical educational institutions and visitors from Moscow and St. Petersburg; their involvement with the conferences was repetitive. Governmental institutions jointly with big pharma were responsible for organisation of these conferences and attracting audience.

Limitations of these observations: Unfortunately, the information on printed-paper conference invitations was not complete because not all tickets have survived. From the interview with the physician we know that in addition to these printed on paper invitations there were many invitations and alerts sent out by e-mail, SMS messages and personal phone calls, making the regularity of these conferences much higher. The physician, who kindly provided this information to us, asked not to be named or thanked in any public presentation of the results of these analyses.

Keywords: Conferences, opinion leaders, health practitioners, physicians, pharmaceutical companies

Conflict of interest statement: We declare that we have no conflict of interest.

\section{References}

[1] Shaderkin VA. Conference of doctors in life. [Internet] 2012 [cited 2012 Dec 14]. Available from: http://uroweb.ru/db/ article/konferentsii-v-zhizni-vrachei

[2] Giovanni A Fava. Should the drug industry work with key opinion leade rs? BMJ. 2008;336(7658): 1404-5. doi: 10.1136/ bmj.39541.702870.59

[3] Soans A. KOL Relationship Management in Pharma Device- Workshop Highlights MedicineMan [Internet]. 2010 Aug 23 [cited 2010 Aug 23]; Available from: http://medicinman.net/download/MedicinMan August 2014.pdf

[4] Arzhanov NA. Pharmacy and medicine: The two sides of the same coin. pharmacist. -2007 Dec; 12-s; 15-17. 